\title{
Kultura i przywództwo w organizacji jako potencjał procesów odnowy organizacyjnej
}

\section{Culture and leadership in an organisation as organisational renewal potential}

\author{
Katrzyna Gadomska-Lila \\ Uniwersytet Szczeciński, e-mail: katarzyna.gadomska@wneiz.pl
}

\begin{abstract}
Streszczenie
Odnowa organizacyjna jest procesem złożonym, a jego skuteczność determinuje wiele czynników. Celem artykułu jest analiza roli kultury organizacyjnej i przywództwa w tym procesie. Na podstawie analiz desk research opisano zależności między poszczególnymi kategoriami. Wyniki analiz potwierdziły, że kultura organizacyjna i będące jej źródłem przywództwo odgrywają bardzo ważną rolę w procesie odnowy organizacyjnej, a nierzadko są wręcz krytyczne dla jej powodzenia. Podstawowe aktywności liderów, zwłaszcza odnoszące się do tworzenia wizji przekształceń oraz budowania sprzyjającej kultury organizacyjnej, są istotnymi determinantami skuteczności procesów odnowy. Pozwala to również wskazać pewne implikacje dla praktyki gospodarczej, w głównej mierze dotyczące kształtowania postaw liderów i kierunków rozwoju pożądanych wzorów kulturowych.
\end{abstract}

Słowa kluczowe: odnowa organizacyjna, potencjał odnowy, kultura organizacyjna, przywództwo.

\begin{abstract}
Organisational renewal is a complex process whose effectiveness is determined by a variety of factors. The aim of the paper is to analyse the role of organisational culture and leadership in this process. Based on desk research, relationships between individual categories have been found. The results show that organisational culture and underlying leadership are crucial to organisational renewal, and frequently even essential to its success. Basic activities undertaken by leaders in relation to the vision of transformations and development of a suitable organisational structure are key determinants of effectiveness of renewal processes. It helps identify certain implications to business practice, mostly those related to promoting desired attitudes among leaders and directions of developing desired cultural patterns.
\end{abstract}

Keywords: organisational renewal, renewal potential, organisational culture, leadership. 


\section{Wstęp}

Problematyka odnowy organizacyjnej, głównie z racji dynamiki i złożoności zmian otoczenia, wymagających reakcji ze strony organizacji chcących przetrwać i rozwijać się, w ostatnim czasie znacznie zyskuje na popularności. Proces odnowy to inicjatywa długotrwała i złożona, zdeterminowana wieloma czynnikami. D. Miller i P. Friesen [1984] wskazują, że istotną rolę $w$ tym procesie odgrywają: styl podejmowania decyzji, struktura, strategia czy też ogólny stan organizacji (konkretna sytuacja, w jakiej się znajduje, zważywszy jej wielkość, okres działania, rodzaj otoczenia itp.), co w badaniach empirycznych potwierdzili m.in. D.L. Lester i J.A. Parnell [2002]. Z kolei V. Santos i T. Garcia [2007], podkreślając kompleksowość procesu odnowy, wskazali na zmiany w otoczeniu jako istotny czynnik determinujący decyzję o kierunku odnowy, a także postawy pracowników wobec zmian, w szczególności zaś postawy liderów. Przeprowadzone przez nich badania wykazały, jak ważne dla powodzenia procesów odnowy są decyzje menedżerów. Kwestie przywództwa stanowiły również przedmiot badań B.M. Bassa i B.J. Avolio [1995] czy B.S. Pawara i K.K. Eastmana [1997]. Ich wyniki akcentują szczególne znaczenie przywództwa transformacyjnego dla poprawy procesów odnowy, w centralnym punkcie umiejscawiając takie aktywności, jak kreowanie wizji i kształtowanie kultury organizacyjnej. Analiza tych uwarunkowań powoduje, że istotnego znaczenia nabiera problem: w jaki sposób zapewnić sprawny przebieg procesu odnowy organizacyjnej? Jaką rolę w tym procesie odgrywa kultura organizacyjna oraz przywództwo i w jaki sposób mogą one przyczynić się do jego skutecznej realizacji?

Celem artykułu jest analiza roli kultury organizacyjnej i przywództwa w procesie odnowy organizacyjnej. Punkt wyjścia prowadzonych rozważań stanowią studia literatury krajowej i zagranicznej, umożliwiające charakterystykę kategorii odnowy organizacyjnej i jej kluczowych determinant. W dalszej części rozważania skierowano na potencjał procesów odnowy, zwłaszcza na kulturę organizacyjną i przywództwo. Przeprowadzone analizy desk research pozwoliły opisać zależności między poszczególnymi kategoriami. Wyniki analiz potwierdziły, że kultura organizacyjna i będące jej źródłem przywództwo odgrywają bardzo ważną rolę w procesie odnowy organizacyjnej, a nierzadko stanowią wręcz punkt krytyczny dla jej powodzenia. Podstawowe aktywności liderów, odnoszące się do tworzenia wizji przekształceń oraz budowania sprzyjającej kultury organizacyjnej, okazały się istotnymi determinantami skuteczności procesów odnowy. Pozwoliło to również wskazać pewne implikacje dla praktyki gospodarczej, w głównej mierze dotyczące kształtowania postaw liderów i kierunków rozwoju pożądanych wzorów kulturowych.

\section{Proces odnowy organizacyjnej i jego determinanty}

Odnowa organizacyjna to kategoria, która w literaturze z zakresu zarządzania, zwłaszcza zarządzania strategicznego, często jest powoływana w kontekście zmian i koncepcji rozwoju organizacji. W procesie wyjaśniania jej istoty poszukuje się odniesień do różnych teorii, umożliwiających głębszą analizę znaczeń, jakie ze sobą niesie. W pracach H.W. Volberdy z zespo- łem [2001], P. Banaszyka i Sz. Cyferta [2007] czy D.L. Lestera i J.A. Parnella [2002] przywołuje się liczne teorie w celu wyjaśnienia procesu odnowy organizacyjnej, a zwłaszcza odnowy strategicznej, i osadzenia ich w pewnym kontekście. Wskazuje się teorię ekologii populacji (M.T. Hannan i J.H. Freeman), instytucjonalną (R. Greenwood i C.R. Hinings), ewolucyjną (R. Nelson i S. Winter), zasobową (J.B. Barney) czy kładącą nacisk na stan otoczenia oraz działania naczelnego kierownictwa, teorię strategicznego wyboru (J. Child, R.E. Miles, C.C. Snow). Współcześnie dominuje bardziej eklektyczne podejście, odwołujące się również do założeń teorii behawioralnych (R.M. Cyert, J.G.March), według których proces odnowy jest uwarunkowany zarówno umiejętnościami organizacji, jak i stopniem kontroli organizacyjnego niedopasowania; teorii uczenia się (C. Argyris, D. Schön, G. Huber), gdzie akcent położony jest na elastyczne dopasowywanie organizacji i otoczenia, oparte na zdolnościach uczenia, oduczania i ponownego uczenia się czy teorii dynamicznego dostosowania i koncepcji zdolności dynamicznych (D.J. Teece, G. Pisano, A. Shuen), postulującej wykorzystanie ukrytych umiejętności organizacji, związanych z rozwojem i dostosowaniem kluczowych kompetencji.

Sam proces odnowy jest złożony i wielowymiarowy. Sz. Cyfert [2012, s. 124] definiuje odnowę organizacyjną jako zmianę formuły działania organizacji, owocującą rekonstrukcją modelu biznesu. Ze względu na to, że dobry model biznesowy musi charakteryzować zbieżność z celami firmy, samowzmacniający się charakter oraz solidność [Casadesus-Masanell, Ricart 2010, s. 76-80], konieczna jest dbałość o te atrybuty, zwłaszcza w sytuacji jego zmiany. Przeformułowanie modelu biznesu to podstawowy, choć nie jedyny warunek skuteczności procesów odnowy. Zmiany modelu determinują bowiem treść, proces i efekt przekształceń kluczowych elementów systemu zarządzania [Cyfert, Bełz, Wawrzynek 2014, s. 16]. Warunkiem skuteczności procesów odnowy organizacyjnej jest zatem systemowe podejście do zmiany funkcjonowania organizacji, obejmujące swoim zasięgiem całą firmę. Sz. Cyfert wskazuje, że owa systemowość odnosi się do trzech warstw: definicyjnej, regulacyjnej i realizacyjnej [Cyfert 2012, s. 125-128]. Podczas gdy w warstwie definicyjnej, nawiązującej do koncepcji modelu biznesu, wskazywany jest wzorzec rozwoju organizacji, w warstwie realizacyjnej określane są sposoby realizacji działań operacyjnych z rozpisaniem ich na procesy i projekty; $\mathrm{w}$ warstwie regulacyjnej, opisywanej przez mechanizmy systemu zarządzania, definiowane są standardy i wzorce działań. Wymaga to przyjęcia określonych rozwiązań i wprowadzenia, właściwych obranym kierunkom, mechanizmów w różnych obszarach funkcjonowania organizacji. Wsparcie wybranego kierunku odnowy jest bowiem kluczowe dla jej sprawnego przebiegu.

Odnowa organizacyjna może być rozpatrywana według różnych kryteriów, a działania związane z realizacją jej założeń mogą przybierać różnorodną postać. Analiza literatury przedmiotu pozwoliła wskazać kluczowe modele, które zestawiono w tab. 1.

Zasadniczo działania związane z odnową organizacyjną mają charakter zmian dostosowawczych, oznaczających adaptację do zaistniałych bądź spodziewanych zmian otoczenia, lub też 
zmian wyprzedzających, wiążących się z antycypacją przyszłych warunków. Dla organizacji oznacza to eksploatowanie dotychczasowych kompetencji bądź też działalność eksploracyjną wiążącą się z dążeniem do zdobycia nowych kompetencji.

Tabela 1. Modele odnowy organizacyjnej wg różnych autorów

\begin{tabular}{|c|c|c|c|}
\hline Autor & $\begin{array}{c}\text { [Banaszyk, Cyfert } \\
\text { 2007] }\end{array}$ & $\begin{array}{c}\text { [Volberda, } \\
\text { Baden-Fuller, Bosch } \\
\text { 2001] }\end{array}$ & $\begin{array}{c}\text { [Allaire, Firsirotu } \\
2000]\end{array}$ \\
\hline Kryterium & $\begin{array}{l}\text { Charakter } \\
\text { i ciągłość zmian }\end{array}$ & $\begin{array}{l}\text { Rodzaj zmian } \\
\text { w otoczeniu, poziom } \\
\text { zaangażowania } \\
\text { menedżerów }\end{array}$ & $\begin{array}{l}\text { Relacja } \\
\text { organizacja- } \\
\text {-otoczenie }\end{array}$ \\
\hline $\begin{array}{l}\text { Modele } \\
\text { procesów } \\
\text { odnowy }\end{array}$ & $\begin{aligned} \text { - } & \text { doskonalenie } \\
& \text { organizacji } \\
\text { - } & \text { dopasowanie } \\
& \text { organizacji } \\
\text { - } & \text { strategiczny } \\
& \text { zwrot } \\
\text { - } & \text { strategiczna } \\
& \text { rewitalizacja }\end{aligned}$ & $\begin{aligned} & \text { - } \text { odnowa } \\
& \text { wyłaniająca się } \\
& \text { - odnowa } \text { odnośrednia } \\
& \text { bezpos } \\
& \text { - odnowa } \text { wspomagana } \\
& \text { - odnowa } \\
& \text { transformacyjna }\end{aligned}$ & 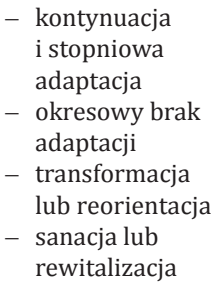 \\
\hline
\end{tabular}

Źródło: opracowanie własne.

Odnowa organizacyjna nie jest jednak dyskretnym przesunięciem organizacji z jednego stanu w drugi. Jest to proces ciągły [Volberda, Baden-Fuller, Bosch 2001, s. 160], przy czym D.L. Lester i J.A. Parnell podkreślają, że jest to proces dynamiczny [Lester, Parnell 2002, s. 60], a jego powodzenie wymaga odpowiedniej kultury organizacyjnej. Podczas gdy pewne strategie, jak doskonalenie organizacji czy kontynuacja i adaptacja stopniowa, zazwyczaj wymagają jedynie modyfikacji pewnych zwyczajów, nawyków czy procedur działania w organizacjach i nie są nadmiernie absorbujące i skomplikowane, zmiany radykalne, takie jak: strategiczny zwrot, ożywienie, transformacja czy reorientacja, wymagają już istotnej ingerencji w sferze kulturowej. Najczęściej oznacza to zmianę kultury w kierunku sprzyjającym zmianom orientacji strategicznej.

Diagnoza stopnia przystosowania organizacji do wymagań otoczenia oraz równoważenia przyszłych i obecnych oczekiwań oraz kształtowanie sprzyjającej kultury organizacyjnej to odpowiedzialność kadry kierowniczej najwyższego szczebla. Obserwując zachodzące w otoczeniu zmiany, menedżerowie coraz częściej utwierdzają się w przekonaniu, że koniecznością staje się rozwijanie zdolności przystosowawczych, czyli umiejętności szybkich zmian w kierunku pojawiających się szans i dostosowania się do zmian na rynkach (organizacje zwinne, innowacyjne i proaktywne), przy jednoczesnym eksploatowaniu własnych zasobów i kompetencji, oraz posiadanie równie ważnej zdolności - wyczucia, jak kreować wartość w krótkim okresie i jakie działania podjąć, żeby ją dostarczyć [Birkinshaw, Gibson 2004, s. 47]. Dla długookresowego powodzenia niezbędne jest łączenie obu podejść. Pojawia się zatem konieczność godzenia swego rodzaju sprzeczności - z jednej strony eksploatacji posiadanych kompetencji, z drugiej - eksploracji, czyli poszukiwania nowych (zob. [Raich et al. 2009, s. 685-695]). Podejścia te nie są jednak alternatywami. Bardziej chodzi o ich równoważenie. Umiejętność, która prowadzi do poszukiwania tej idealnej równowagi, określa się jako oburęczność (ambidexterity). Dotyczy to napięć pomiędzy upo- rządkowaniem a adaptacją - lub jeszcze szerzej: pomiędzy teraźniejszością a przyszłością [Gibson, Birkinshaw 2004, s. 209-226]. W praktyce funkcjonowania organizacji oznacza to połączenie dwóch rodzajów działalności - tworzenia przełomowych innowacji i ciągłego doskonalenia dotychczasowych produktów i usług [O’Reilly, Tushman 2004]. Mimo że oba podejścia istotnie się różnią, nie powinny być traktowane jako alternatywne, lecz jako komplementarne, gdyż tylko ich właściwa kombinacja może przynieść spodziewane, pozytywne efekty. Wymaga to z kolei odpowiedniego przywództwa, umożliwiającego współistnienie eksploatacji i eksploracji, które M.L. Tushman, W.K. Smith i A. Binns [2011, s. 44] nazywają „przywództwem oburęcznym”. Menedżerowie muszą z jednej strony rozwijać podstawowe obszary działalności, co wymaga pilnowania kosztów, a z drugiej - poszukiwać innowacji, czyli wejść w rolę wizjonerskich przedsiębiorców, ostatecznie zachowując obiektywizm potrzebny do wypracowania kompromisów.

Bez względu jednak na charakter przekształceń realizowanych w ramach odnowy organizacyjnej - czy mają bardziej ewolucyjny, czy rewolucyjny charakter, czy też może poszukuje się równowagi między nimi, kwestie przywództwa oraz kultury organizacyjnej stają się decydujące. Im bardziej radykalny charakter zmian, tym nabierają one większego znaczenia.

\section{Znaczenie kultury i przywództwa w procesie odnowy organizacyjnej}

Zdaniem H. Schwartza i S.M. Davisa, właściwie każda zmiana w organizacji może nieść ze sobą „ryzyko kulturowe” [1981, s. 36-37]. Skala tego ryzyka zależy głównie od tego, jakie znaczenie dla powodzenia organizacji ma przyjęta koncepcja zmian i w jakim stopniu jest ona zgodna $\mathrm{z}$ istniejącą obecnie kulturą.

Analizując wpływ dotychczasowej kultury organizacyjnej na funkcjonowanie organizacji, warto rozważyć trzy aspekty: kierunek wpływu - czy kultura wpływa na zachowanie członków w taki sposób, że cele organizacji są osiągane, czy stymuluje zachowania sprzeczne z oficjalną misją i celami; przenikliwość wpływu - czy widoczne są istotne różnice w postrzeganiu kultury przez poszczególnych pracowników; siła wpływu - czy członkowie czują się zmuszeni do wypełniania nakazów kultury, czy też uważają, że kultura tylko sugeruje określone sposoby zachowania (Kilmann et al., za [Bjerke 2004, s. 59-60]). Nawet jeśli kultura jest silna, wyrazista i głęboko zakorzeniona w postawach i zachowaniach pracowników, nie musi oznaczać niezdolności do przeprowadzenia niezbędnych zmian. R. Pascale dowodzi [1985, s. 37], że wiele organizacji o wyrazistej kulturze dobrze sobie radzi z wprowadzaniem nowych rozwiązań. Należy zgodzić się z tym poglądem. Badania autorki zrealizowane w 2013 roku w jednym z oddziałów międzynarodowego koncernu, potwierdziły również, że mimo silnie zakorzenionych wzorów kultury narodowej i znaczących różnic kulturowych, udaje się wprowadzić zakładane zmiany i ukształtować wzory postępowania sprzyjające ich realizacji. Na ogół jednak, głównie z racji swoich atrybutów (tj. konserwatyzm, opór wobec zmian, ciągłość, stabilność), kultura sprzyja raczej ochronie status quo niż zmianom, zwłaszcza 
zmianom radykalnym, takim jak transformacja czy rewitalizacja. Tymczasem warunki, w których funkcjonuje większość współczesnych organizacji, wymuszają konieczność tworzenia programów ciągłej zmiany, co oznacza kształtowanie kultury elastycznej, innowacyjnej, adaptacyjnej, efektywnej i mobilnej (por. [Skalik 1997, s. 10-11]) oraz, jak dodają A. Zgrzywa-Ziemak i R. Kamiński [2009, s. 180] - kultury otwartej, sprzyjającej zmianom i organizacyjnemu uczeniu się.

Nosicielami kultury są menedżerowie, a zwłaszcza liderzy. Wybory, jakich dokonują, szczególnie decyzje związane ze stosunkiem do otoczenia i z przyjętą strategią, odzwierciedlają ich podejście do rzeczywistości i kształtują oczekiwane zachowania pozostałych pracowników [Schwartz, Davis 1981, s. 35]. Jako kluczowe dla sukcesu procesu odnowy wymienia się trzy czynniki inicjowane przez menedżerów [Lester, Parnell 2002, s. 60-61]: kreowanie otoczenia wspierającego dobrą komunikację w czasie rzeczywistym, nacisk na redukcję niepewności podczas eksperymentowania i uczenia się oraz odnoszenie bieżących projektów do przewidywalnych przyszłych warunków. Szczególne znaczenie dla skuteczności procesu odnowy ma sprawna realizacja przywódczej roli menedżerów. To liderzy odpowiadają bowiem za wyznaczanie kierunku, korygowanie postaw i motywowanie pracowników do osiągania celów organizacji [Huff et al. 2011, s. 414]. Jak to określają Y. Allaire i M.E. Firsirotu [2000, s. 312], „ucieleśniając przedsiębiorstwo”, jego nowe wartości i orientacje, lider może się stać najbardziej skutecznym podmiotem procesu zmiany, wzorcem nowych wartości i norm zachowania, które stały się istotne z punktu widzenia przetrwania i sukcesu organizacji. Twierdzi się nawet, że funkcją przywództwa jest „tworzenie kultury i zarządzanie nią" [Schein 1985, s. 171].

Zmiana kultury to proces złożony i długotrwały, powinien się zatem sprowadzać do ciągłego kształtowania przez kadrę menedżerską postaw sprzyjających zmianom. Dlatego też zdolność kształtowania/zmiany kultury organizacyjnej jest swego rodzaju testem przywództwa. Jak bowiem pisze A.K. Koźmiński [2013b, s. 8], „przywództwo dotyczy celów przełomowych i wyjątkowo niesprzyjających warunków, stanów turbulencji". Skupione na pozycjonowaniu organizacji w otoczeniu, określane jest mianem przywództwa strategicznego [Ireland, Hitt 1999, s. 43-57]. Źródłem jego sukcesu jest umiejętność budowania zaangażowania pracowników i skierowania ich energii ku przekształcaniu organizacji. Głównym przedmiotem zainte- resowania liderów strategicznych coraz częściej jest kształtowanie wizji i kultury organizacji oraz zwiększanie umiejętności i możliwości jej członków. Wizja strategiczna i kultura organizacji wyznaczają pewne ramy czy też kontekst decyzyjny, w którym członkowie podejmują codzienne decyzje, spójne z określonymi kierunkami strategicznymi [Huff et al. 2011, s. 416].

Kierunek zmian oraz powodzenie ich realizacji w istotnej mierze są zdeterminowane systemem wartości i postawą lidera, od którego oczekuje się przede wszystkim jasnej wizji i jej klarownej prezentacji oraz kształtowania kultury organizacyjnej sprzyjającej jej urzeczywistnianiu. Istotne zatem staje się zdefiniowanie zależności i kierunku wpływu kultury i przywództwa na powodzenie procesu odnowy organizacyjnej. Model takich relacji zaprezentowano na rys. 1 .

Z perspektywy skutecznej realizacji procesów odnowy dwie aktywności liderów są kluczowe - tworzenie i realizacja wizji oraz kształtowanie sprzyjającej kultury organizacyjnej. Istotą przywództwa jest bowiem wywieranie wpływu na innych i tworzenie wizji zmiany [Kotter 1990]. Początkowo wizja ma bardzo ogólny zarys i jest najczęściej efektem twórczej pracy jednej osoby. Z czasem nabiera wyrazistości, a w ślad za nią pojawia się strategia służąca jej realizacji. Z racji tego, że proces odnowy nie ma szans powodzenia, jeśli wizja przekształceń nie uzyska poparcia pozostałych pracowników, bardzo ważne jest również komunikowanie wizji. Niezbędne jest dostarczanie pracownikom wiarygodnych informacji (swoista kampania informacyjna na temat zmian), i to wszelkimi możliwymi kanałami (biuletyny firmowe, narady i zebrania, szkolenia itp.), które mogą służyć popularyzacji przekształceń. Istotnego znaczenia nabiera przy tym sposób zachowania liderów, których działania muszą być spójne z założeniami głoszonej wizji i wynikającymi z niej deklaracjami. Potrzebne jest również wsparcie realizacji nowej koncepcji. Lider powinien określić, w jaki typ zasobów, kompetencji i technologii organizacja będzie inwestować. Oznacza to również właściwe konfigurowanie elementów organizacji, sprzyjające urzeczywistnianiu projektu zmian. Z badań nad dopasowaniem organizacyjnym, przeprowadzonych przez autorkę [Gadomska-Lila 2013], wynika, że spójność (w tym przypadku strategii, kultury organizacyjnej i zarządzania zasobami ludzkimi) ma ważne konsekwencje dla sprawnego funkcjonowania organizacji - pozytywnie wpływa na postawy i zachowania pracowników, a pośrednio również

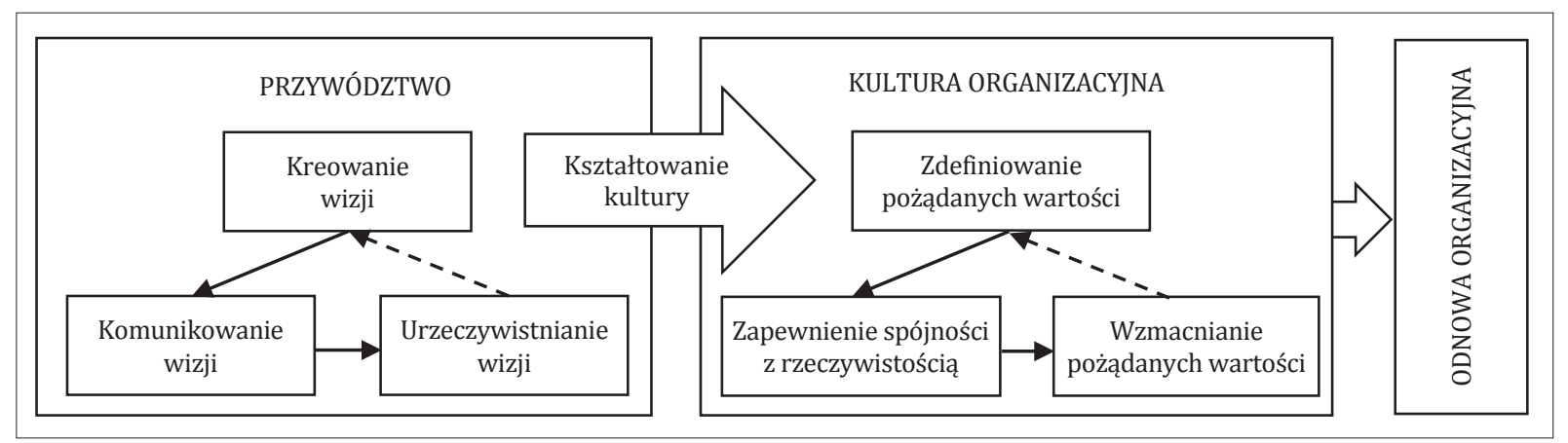

Rysunek 1. Zależności między kulturą organizacyjną, przywództwem i odnową organizacyjną

Źródło: opracowanie własne. 
na wyniki organizacji. W procesie odnowy organizacyjnej, zwłaszcza w sytuacji radykalnej zmiany, konieczne jest wypracowanie takiego programu działań, który umożliwi odpowiednie skoordynowanie i zsynchronizowanie różnych wymiarów. Program taki powinien być konsekwentny i spójny. Powinien urzeczywistniać wszystkie deklarowane wartości i działania, aby nie powodować dysonansu między deklaracjami a codziennym funkcjonowaniem organizacji. Brak spójności niesie za sobą ryzyko kreowania niepożądanych postaw pracowników, negatywnie oddziałujących na wyniki organizacji [Allaire, Firsirotu 2000, s. 310]. Skuteczny przywódca powinien tak postępować, aby członkowie organizacji zrozumieli jego zamierzenia i uczestniczyli w definiowaniu celów, strategii, sposobów i systemów prowadzenia działalności, które mają być wdrażane. Powinien pamiętać, że ludźmi zarządza się nie tyle przez różnego rodzaju środki techniczne, ile przez „subtelne sygnały kulturowe" [Pascale 1985, s. 34]. W sytuacji radykalnych zmian bardzo skuteczne okazuje się zarządzanie symboliczne. Opiera się ono na daleko posuniętym zrozumieniu mechanizmów społecznych leżących u podstaw symboli, znaczeń i mitów. Wykorzystuje mechanizmy retoryki i perswazji i ukierunkowuje je na pożądane zmiany [Allaire, Firsirotu 2000, s. 306-310], co pomaga budować zaangażowanie w projekt zmian. Dotyczy wartości, postaw i mentalności, które należy wzbudzić, aby zrealizować właściwe strategie i osiągnąć wyznaczone cele.

Bardzo ważne jest jasne zdefiniowanie pożądanych wartości, których przestrzeganie znacząco wesprze realizację procesu odnowy. Wartości stanowiące podstawę kultury organizacyjnej dają zatrudnionym poczucie zmierzania w jednym kierunku i wskazują pożądane zachowania. Wspólne wartości grają rolę nieformalnego systemu kontroli, który informuje pracowników, czego się od nich oczekuje [Deal, Kennedy 1988, s. 21-33]. Należy w pełni podzielić ten pogląd, gdyż obserwacja praktyki gospodarczej i przykłady wielu firm potwierdzają, że w sytuacji gdy wartości są jasno zdefiniowane i znane pracownikom, częściej przejawiają oni oczekiwane postawy i zachowania w porównaniu z firmami, w których brakuje czytelnych wzorów kulturowych. Przykładem jasno zdefiniowanych wartości może być wskazanie na efektywność, unikanie ryzyka, jakość, zadowolenie klientów itp., ważnych dla realizacji strategii eksploatacji dotychczasowych kompetencji, bądź też pożądanych w procesie eksploracji nowych kierunków - eksperymentowanie, podejmowanie ryzyka, elastyczność, szybkość itp. Zdefiniowanie kluczowych wartości i ich znajomość przez pracowników to warunek bardzo ważny, jednak niewystarczający dla powodzenia procesu odnowy. Deklaracje muszą znaleźć odzwierciedlenie w rzeczywistości; muszą być powszechnie podzielane, jeśli mają działać. Postawy i zachowania pracowników zgodne z wartościami kultury organizacyjnej powinny być natomiast doceniane, by w ten sposób utrwalać pożądane wzory kulturowe. Takie rozwiązania przyjęto w procesie realizacji zmiany kulturowej w koncernie azjatyckim, co zaobserwowano podczas badań autorki, wspomnianych we wcześniejszej części opracowania. Przyniosły one na tyle pozytywne skutki, że stały się trwałym elementem systemu motywacyjnego.
Dotychczasowe rozważania i zarysowane zależności pozwalają stwierdzić, że przywództwo i kultura są ze sobą ściśle związane. Do tego stopnia, że E. Schein [1985] określa je jako awers i rewers tej samej monety. Dla powodzenia procesu odnowy szczególne znaczenie ma przywództwo transformacyjne. Ludzie podążają bowiem za tymi, którzy potrafią ich inspirować, zachęcać do działania, budzić wolę działania i zaangażowanie. Przywódca transformacyjny to człowiek z wizją i pasją, pełen energii i entuzjazmu. Coraz większego znaczenia, również w kontekście budowania przewagi konkurencyjnej, nabiera zatem to, co do tej pory było często marginalizowane - emocje, zaangażowanie i wyobraźnia. Kluczem do tego jest, jak twierdzą K. Krzakiewicz i Sz. Cyfert, przywództwo sensualne, które rozwija się dzięki wyobraźni i emocjom, ale jednocześnie jest „dostatecznie efektywne”. Relacje z pracownikami budowane są poprzez odczucia, intuicję i oczekiwania [Krzakiewicz, Cyfert 2013, s. 4-8], co potwierdza tezę A.K. Koźmińskiego [2004, s. 154], że przywódca jest „technikiem ludzkich emocji”.

Przywódcy transformacyjni są wizjonerami, którzy potrafią wybiegać myślami daleko w przyszłość, a jednocześnie są promotorami zmian, które mają tam zaprowadzić organizację. Potrafią podjąć ryzyko i przeciwstawić się status quo, kierując się nadrzędnym interesem organizacji. Przestrzegają wartości ich zachowania są całkowicie zgodne $\mathrm{z}$ deklaracjami. Radzą sobie w sytuacjach złożonych, wieloznacznych i niepewnych. Błędy traktują jako ważne doświadczenia, dzięki którym mogą się stale uczyć [Tichy, Devanna 1986, s. 271-280]. Przywództwo transformacyjne opiera się na takich działaniach lidera, jak (por. [Koźmiński 2013a, s. 209-210]):

- zindywidualizowana troska o pracowników i tworzenie im optymalnych warunków rozwoju,

- pobudzanie kreatywności i zachęcanie do poszukiwania niekonwencjonalnych rozwiązań,

- inspirowanie i motywowanie oparte na wizji, która jest komunikowana tak, by wyzwolić pełne zaangażowanie, a nawet entuzjazm,

zaszczepianie idealistycznych wzorców, wzbudzających dumę, respekt i zaufanie.

Realizacji tych działań sprzyjają umiejętności przewidywania, tworzenia wizji, dostosowania wartości, mobilizowania pracowników i delegowania zadań. W perspektywie silnej dynamiki zmian kluczową umiejętnością jawi się zdolność szybkiego reagowania na zmiany. Oznacza to nie tylko aktywną pracę liderów w zakresie formułowania i wdrażania strategii, lecz także włączania $\mathrm{w}$ ten proces pracowników. Wiąże się to z poszerzaniem zakresów odpowiedzialności i uprawnień. A.S. Huff, S.W. Floyd, H.D. Sherman, S. Terjesen [2011, s. 416] nazywają to „współprzywództwem”. Podkreślają również, że wymaga ono od członków organizacji rozumienia jej celów i powszechnego zaangażowania. Słuszna to teoria i warto praktykować jej założenia, zachęcając pracowników do większej aktywności w obszarze decydowania o kierunkach rozwoju organizacji. Problem w tym, że w wielu organizacjach inicjatywa programu odnowy wychodzi najczęściej od jednej osoby, gdy tymczasem, jak podkreśla J.P. Kotter, udana realizacja procesu odnowy organizacyjnej wymaga „koalicji liderów”. Przykłady firm, które proces odnowy przeszły z sukcesem, wskazu- 
ją, że w zależności od wielkości organizacji, liczba osób angażujących się w przeprowadzenie procesu odnowy wynosiła od kilku do kilkudziesięciu [Kotter 2007, s. 12-13]. Sprawna realizacja wymaga koalicji liderów, silnej pod względem miejsca w hierarchii, rangi w organizacji, dostępu do informacji i fachowej wiedzy, sieci kontaktów, a także uznania, jakim cieszą się wśród pracowników.

Rolą liderów jest nie tylko skuteczne przeprowadzenie procesu odnowy, lecz także utrwalenie jej efektów. Jak to określa J.P. Kotter [2007, s. 24] - zmiany muszą „przeniknąć do krwiobiegu firmy". Odbywa się to poprzez uświadamianie pracownikom, w jaki sposób nowe podejście sprzyja funkcjonowaniu organizacji (jej sprawności, efektywności, dalszemu rozwojowi itp.), skłanianie nowych menedżerów, by utożsamiali się z wprowadzonymi zmianami, oraz wzmacnianie kultury organizacyjnej poprzez utrwalanie nowych wzorów kulturowych.

\section{Zakończenie}

Dynamika zmian otoczenia, ich złożoność, kompleksowość i nieprzewidywalność, prowadzi wiele organizacji w kierunku odnowy organizacyjnej. Proces odnowy jest wielowymiarowy i długotrwały, a jego skuteczna realizacja zdeterminowana wieloma czynnikami. Kultura i przywództwo to jedne z kluczowych kategorii w tym procesie. Kierunek zmian oraz powodzenie ich realizacji w istotnej mierze są bowiem zdeterminowane systemem wartości i postawą lidera, od którego oczekuje się przede wszystkim jasnej wizji i jej klarownej prezentacji oraz kształtowania kultury organizacyjnej sprzyjającej jej urzeczywistnianiu. Przeprowadzone studia literaturowe, analiza wyników badań różnych autorów, a także obserwacja praktyki gospodarczej skłaniają do sformułowania w tym względzie kilku kluczowych wniosków:

Odnowa organizacyjna to proces kompleksowy, mający swe implikacje w różnych sferach funkcjonowania organizacji. Systemowy charakter tego procesu sprawia, że wymaga on ingerencji w wielu obszarach. Zakres podejmowanych działań zależy od przyjętego kierunku oraz sposobu przekształceń. Im bardziej radykalne zmiany, tym większa skala ingerencji, a co za tym idzie, większa potrzeba wsparcia w realizacji programu odnowy.

Istnieją różne modele oraz koncepcje odnowy organizacyjnej. Może to być m.in. adaptacja, transformacja czy rewitalizacja bądź też poszukiwanie równowagi między eksploatacją i eksploracją, co oznacza budowanie organizacji oburęcznej. Obrany kierunek wymaga określonego kontekstu. Z tego względu istotnymi czynnikami potencjału odnowy stają się kultura i przywództwo.

- Kultura organizacyjna to ważny składnik potencjału odnowy. Pod warunkiem celowego kształtowania pożądanych wzorów kulturowych, zgodnych z obranym kierunkiem odnowy, może stanowić cenne wsparcie w trakcie realizacji tego procesu. Rola kultury wzrasta wraz ze skalą prowadzonych zmian.

- Kolejny ważny element w procesie odnowy organizacyjnej to przywództwo. Podstawowe aktywności liderów, związane z tworzeniem wizji przekształceń oraz budowaniem sprzyjającej kultury organizacyjnej, istotnie deter- minują skuteczność procesów odnowy. W procesie zmian, zwłaszcza w promowaniu zmiany kulturowej, bardzo dobrze sprawdza się przywództwo transformacyjne. Ma to określone implikacje dla praktyki, wiążące się z koniecznością rozwoju takich umiejętności, które pomogą zrealizować program przekształceń oraz kształtować właściwe postawy.

Złożoność problematyki i jej ranga sprawiają, że temat nadal pozostaje aktualny. Rysują się bowiem kolejne, warte eksploracji, obszary badawcze związane z kwestiami przywództwa i kultury w procesie odnowy organizacyjnej, jak np. budowanie kultury uczenia się oraz definiowanie dynamicznych zdolności kluczowych dla realizacji tego procesu.

\section{Literatura}

Allaire Y., Firsirotu M.E., 2000, Myślenie strategiczne, Wydawnictwo Naukowe PWN, Warszawa.

Banaszyk P., Cyfert Sz., 2007, Strategiczna odnowa przedsiębiorstwa, Difin, Warszawa.

Bass B.M., Avolio B.J., 1995, Multifactor Leadership Questionnaire for Research, Mind Garden, Inc, Palo Alto (CA).

Birkinshaw J., Gibson C., 2004, Building ambidexterity into an organization, MIT Sloan Management Review, Summer, s. 47-55.

Bjerke B., 2004, Kultura a style przywództwa, Oficyna Ekonomiczna, Kraków.

Casadesus-Masanell R., Ricart J.E., 2011, Jak skonstruować zwycięski model biznesowy, Harvard Business Review Polska, wrzesień, s. 74-85.

Cyfert Sz., 2012, Systemowy model organizacji: Perspektywa procesów odnowy organizacyjnej, Prace Naukowe Uniwersytetu Ekonomicznego we Wrocławiu, nr 276, s. 124.

Cyfert Sz., Bełz G., Wawrzynek Ł., 2014, Wpływ burzliwości otoczenia na efektywność procesów odnowy organizacyjnej, Organizacja i Kierowanie, $\mathrm{nr} 1 \mathrm{~A}$, s. 16.

Deal T., Kennedy A., 1988, Corporate Cultures, London, Penguin Books.

Gadomska-Lila K., 2013, Dopasowanie organizacyjne. Aspekt strategii, kultury organizacyjnej i zarzq̨dzania zasobami ludzkimi, Difin, Warszawa.

Gibson C., Birkinshaw J., 2004, The antecedents, consequences and mediating role of organizational ambidexterity, Academy of Management Journal, vol. 47, no 2, s. 209-226.

Hatch M.J, Kostera M., Koźmiński A.K., 2010, Trzy oblicza przywództwa: menedżer, artysta, kapłan, Wydawnictwo Akademickie i Profesjonalne, Warszawa.

Huff A.S., Floyd S.W., Sherman H.D., Terjesen S., 2011, Zarządzanie strategiczne, Oficyna Wolters Kluwer business, Warszawa.

Ireland D., Hitt M., 1999, Achieving and maintaining strategic competitiveness in the 21st century: The role of strategic leadership, Academy of Management Executive, no 13, s. 43-57.

Kotter J.P., 1990, A Force for Change: How leadership differs from management, Free Press, New York.

Kotter J.P., 2007, Przewodzenie procesowi zmian: przyczyny niepowodzeń, [w:] Przywództwo w okresie zmian, Harvard Business School Press, Helion, Gliwice.

Koźmiński A.K., 2004, Zarządzanie w warunkach niepewności, Wydawnictwo Naukowe PWN, Warszawa. 
Koźmiński A.K., 2013a, Ograniczone przywództwo. Studium empiryczne, Poltext, Warszawa.

Koźmiński A.K., 2013b, Tajemnice przywództwa, Management and Business Administration. Central Europe, vol. 21, nr 1.

Krzakiewicz K., Cyfert Sz., 2013, Przywództwo sensualne w procesie zarządzania organizacją, Przegląd Organizacji, nr 6, s. 4-8.

Lester D.L., Parnell J.A., 2002, Aligning factors for successful organizational renewal, Leadership \&Organization Development Journal, vol. 23, no 2, s. 60-67.

Miller D., Friesen P., 1984, A longitudinal study of the corporate life cycle, Management Science, vol. 30, s. 1161-1183.

O’Reilly Ch.A., Tushman M.L., 2004, Oburęczna firma, Harvard Business Review, lipiec, no 17

Pascale R., 1985, The paradox of corporate culture: Reconciling ourselves to socialization, California Management Review, XXVII (2), S. 26-41.

Pawar B.S., Eastman K.K., 1997, The nature and implications of contextual influences on transformational leadership: A conceptual examination, Academy of Management Review, 22, s. 80-109.

Raich S., Birkinshaw J., Probst G., Tushman M., 2009, Organizational ambidexterity: Balancing exploitation and exploration for sustained performance, Organization Science, vol. 20, no 4, s. 685--695.
Santos V., Garcia T., 2007, The complexity of the organizational renewal decision: The management role, Leadership\&Organization Development Journal, vol. 28, no 43, s. 336-355.

Schein E., 1985, Organizational Culture and Leadership, Jossey-Bass, San Francisco.

Schwartz H., Davis S.M., 1981, Matching corporate culture and business strategy, Organizational Dynamics, Summer, s. 30-48.

Skalik J., 1997, Współczesne kierunki i formy zmian w organizacjach dynamicznych, Prace Naukowe Akademii Ekonomicznej we Wrocławiu, nr 779.

Tichy N.M., Devanna M.A., 1986, The Transformational Leader, John Wiley\&Sons, New York.

Tushman M.L., Smith W.K., Binns A., 2011, Oburęczne przywództwo, Harvard Business Review, July-August, no 101/102.

Volberda H.W., Baden-Fuller Ch., Bosch F.A.J., 2001, Mastering strategic renewal: Mobilising reneval journeys in multi-unit firms, Long Range Planning, vol. 34, no 2.

Zgrzywa-Ziemak A., Kamiński R., 2009, Rozwój zdolności uczenia się przedsiębiorstwa, Difin, Warszawa. 